\title{
A real site application of a diagnose method at Estimating Insulated Cables Degradation using Non Linearity Indicators
}

\author{
L. N. Velasco ${ }^{1}$, A. Reis ${ }^{1}$, J. C. Oliveira ${ }^{1}$, L. C. G. Freitas ${ }^{1}$, A. P. Finazzi ${ }^{2}$, F. N. Lima ${ }^{2}$, \\ H.C. Martins ${ }^{3}$, W. J. Araújo ${ }^{3}$, J. M. Borges ${ }^{3}$ \\ ${ }^{1}$ Federal University of Uberlândia (UFU), Faculty of Electrical Engineering - Uberlândia (Brazil) \\ email: loana.velasco@gmail.com, reialex@gmail.com, jcoliveira@ufu.br, lcgfreitas@yahoo.com \\ ${ }^{2}$ Federal University of Mato Grosso (UFMT), Electrical Engineering Department - Cuiabá (Brazil) \\ email:apfinazzi@cpd.ufmt.br, fernandn@terra.com.br \\ ${ }^{3}$ Companhia Energética de Minas Gerais (CEMIG) - Belo Horizonte (Brazil) \\ email: hcm@cemig.com.br, ust@cemig.com.br, jonmil@cemig.com.br
}

\begin{abstract}
The quality of electricity supply, among other issues, deals with continuity indicators as one of the most important factors for the characterization of an adequate service as far as power quality is concerned. In this context, one of the major problems responsible for the unscheduled interruptions is related to the degradation of electrical cables insulation and the well-known water tree effect emerges as an important cause for the deterioration of their insulation layer. If this phenomenon happens large loss of insulating properties of dielectric material used to build up such component will occur. In light of these facts, the development of procedures to evaluate, predict and indicate the operational status of operating cables shows highly attractive in order to improve the quality and reliability of energy supply. Focusing this subject, this paper presents a synthesis of existing methods and a new trend towards the mentioned matter. By using experimental measurements, carried out in medium voltage commercial operating cables in a distribution utility throughout non-invasive approach, applied voltage and insulating leakage currents are obtained so support the analysis. The data are used to obtain degradation indexes to estimate the cables physical operational conditions and the found indicators are further considered in viewing the effectiveness of the strategies for the diagnosis purposes.
\end{abstract}

\section{Key words}

Degradation indexes, XLPE insulated cable, Leakage current, Cable diagnosis, Power quality, Water tree.

\section{Introduction}

Authors of accepted abstracts will be requested to submit Questions related to power quality definitely challenge engineers all over the world. Amongst these, the matter of energy supply reliability emerges as an important point towards the improvement of continuity indexes such as the duration and frequency of interruptions. In this way, the information associated to the operational conditions of equipment such as transformers, power cables, etc. has a relevant role in the behavior of the electrical system.

Among the most prominent phenomena responsible for the degradation of power cables, the water tree deterioration consists in a relatively common problem that is developed in the insulation layer of these components. Usually, it occurs when power cable is immersed in humid environment and presents voids and impurities inside the insulation or protrusions in the semiconductor layer of a XLPE cable [1]. As water tree degradation advances, the leakage current waveform, established between inner conductor, insulation layer and ground mesh, show changes in both magnitude and its waveform. Such factors may evidence that the component lifetime is significantly compromised [2].

Aiming the diagnosis of the operational conditions of an insulated cable, in terms of life expectance, several methods have been developed and employed to support decisions about the appropriateness of various actions, ranging from repairs up to replacement or this component. In particular, seeking practical ways for determining the final effects of water tree phenomena on cable degradation and observing studies about modeling and diagnosis, several research, like those presented in [1-9], are intended to propose procedures to detect this kind of failure through the extraction of information from performance parameters that indicate the degradation level of the insulation layer of a power cable. The methods found in the aforementioned references have different approaches to ascertain power cable status. Some examine the component in a de-energized condition while others are based on measurements carried out with an energized cable but without load. The reference [10] describes a synthesis of these strategies. 
Research conducted and described in [10-13], complementary to the state of art of the theme, report contributions towards the establishment of mathematical models to represent and simulate water tree phenomena and, from sampled data, shows directions to obtain performance indexes that indicate the operational state of insulated cables.

Advancing in this topic, this paper is focused in the performance assessment of procedures traditionally used to determine the state indicators of power cables. Additionally, some investigations are conducted about complementary procedures, based in the pattern of nonlinearity of leakage current waveform and related to water tree phenomena. The diagnostic work contemplates, mainly, commercial cables used in an underground energy distribution system and involves relatively new and old cables.

\section{Electrical Model of Insulated Cables with Water Tree Degradation}

The mechanism involved in the leakage current circulation in a power cable, in a path constituted by the conductor, dielectric material and shielding connected to the ground may be, summarily, understood through Fig. 1. This figure clarifies that the conductive material itself is identified by (A) while the cable shielding, which is external to the insulation material, is indicated by (B). This outermost surface is metallic and offers protection and security for the cable through your connection to one or more grounding points. In this way, this constructive structure provides a geometric configuration responsible for the existence of a capacitive effect, similar to those obtained by an association of two concentric cylindrical material separated by any chemical insulator. This implies the existence of an equivalent capacitor, coming from an ideal situation, which, for practical purposes, can be further complemented by an equivalent resistance that represents the active part of leakage currents. Therefore, the equivalent circuit associated with the existence of recognized leakage currents is, ideally, presented as an arrangement of resistive and capacitive components. Figure 2 provides a cross section of the insulated cable in analysis.

A

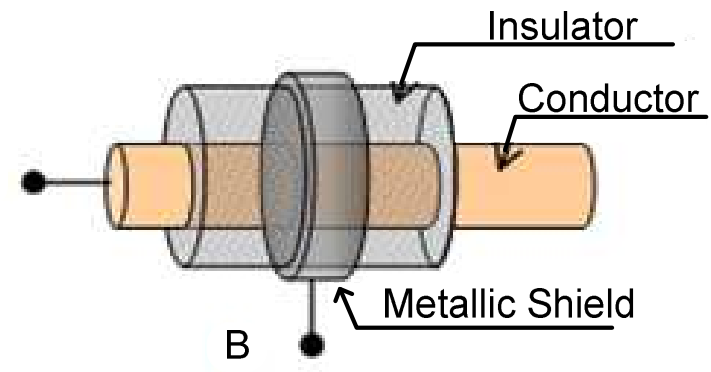

Fig. 1 - Physical design of an insulated cable

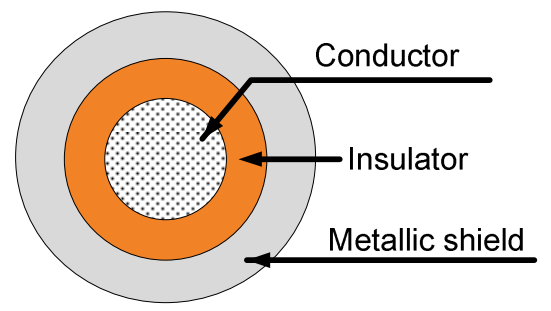

Fig. 2 - Representative cross section of an insulated cable As defined above, without the presence of anomalous effects due to natural degradation, which can appear in actual situations, the cable can be represented as an RC circuit, as shown in Fig. 3. In light of this physical design, it is evident the existence of a current established between the conductor and the shield, which is composed of two components, an active and a reactive, where the latter being dominant in the system. For the purposes of this paper, the capacitive (reactive) component is identified by $\mathrm{i}_{\mathrm{C} 0}$ and the resistive (active) component by $\mathrm{i}_{\mathrm{R} 0}$. The time domain representation is adopted to reproduce current and voltages across the circuit due to the need of know their waveforms.

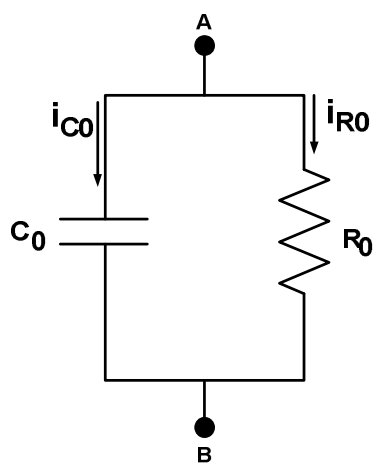

Fig. 3 - Equivalent simplified circuit for a stretch of an insulated cable without degradation.

Assuming that a specific cable presents an insulation composed by degraded and healthy portions, as symbolically shown in the Fig. 4, the electrical model to be established should consider these two situations.

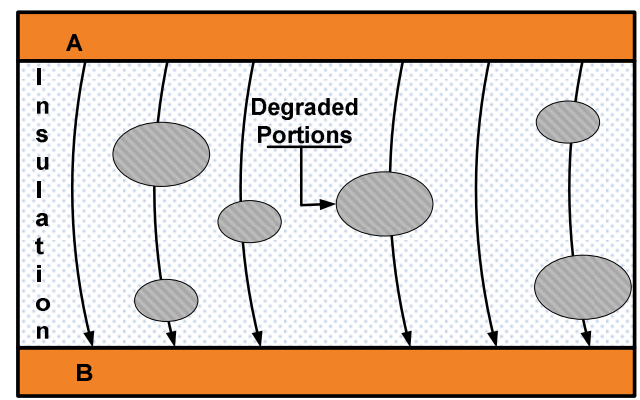

Fig. 4 - Physical interpretation of degraded areas in insulated cables.

The equivalent model to represent the non-degraded areas in the cable insulation consists of a RC combination aforementioned, despite the values to be assigned to these parameters, since not all the surface is under normal operation conditions. Regarding the portions of dielectric material that present the problems described in this paper, it must be noted that they behave with non-linear characteristics, as mentioned in some publications on the subject [1-2]. Faced with this scenario, the adoption of 
linear parameters is no longer an appropriate choice to represent the degraded portions, which leads towards other strategies.

For understandable reasons, the search for models that meet the requirements imposed by a non-linear relationship between voltage and current at the terminals of damaged stretch involves, necessarily, the use of devices that are compatible with such requirements, like nonlinear resistors, surge suppressors, power electronics semiconductors, etc. To illustrate this fact, the Fig. 5 represents the ratio of voltage versus current for a nonlinear component, which, for the purposes of this paper, could represent the region of a cable with insulation degraded. It is worth noting that more linear is the relationship between the quantities, less degraded is the cable insulation. In this case, it should be established a relationship between the applied voltage to the cable and the corresponding leakage current.

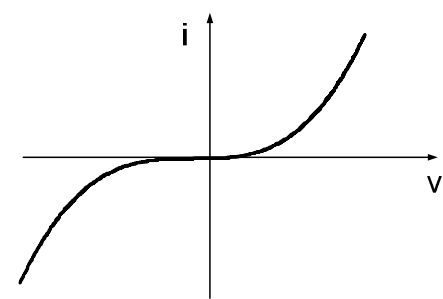

Fig.5 - V-I characteristic for the degraded portion of the insulation due to the water tree phenomenon.

In light of facts previously exposed, it is evident that the model to represent a cable stretch, which is constituted by normal and deteriorated regions, can be conceived by a combination of equivalent circuits composed of linear and nonlinear components. Therefore, Figure 6 shows the physical conception and allows noting two different and complementary circuits. The first one is destined to represent the healthy portion of the cable (multiple RC sets combined in a parallel association). The second one is composed by a series combination of a nonlinear arrangement, which includes a nonlinear resistance and is intended to represent the insulation damage, and a linear circuit, aiming to indicate the healthy regions around water tree deterioration. Naturally, the values assigned to these parameters will dictate the level of degradation involved in each situation under analysis.

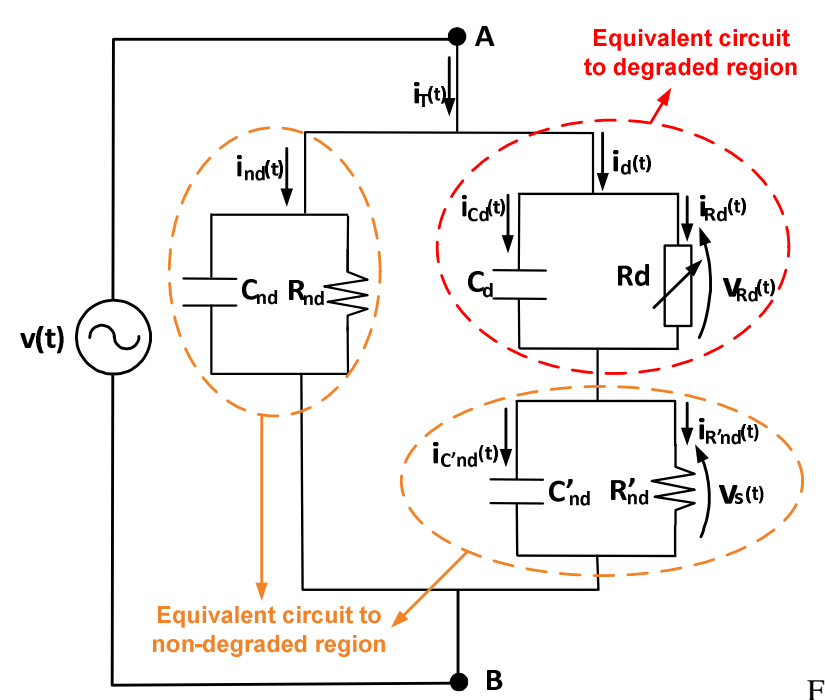

Fig.6 - Equivalent circuit which comprises healthy and degraded parts, for a given length of cable.

In Fig. 6:

- $\mathrm{C}_{\mathrm{nd}}-$ Equivalent capacitance to the non-degraded cable extension;

- $\mathrm{R}_{\mathrm{nd}}-$ Equivalent resistance to the non-degraded cable extension;

- $\mathrm{C}_{\mathrm{d}}-$ Equivalent capacitance to the degraded region along the deteriorated cable insulation extension;

- $\mathrm{R}_{\mathrm{d}}-$ Equivalent resistance to the degraded region along the deteriorated cable insulation extension.

- $\mathrm{C}_{\text {nd }}$ - Equivalent capacitance to the non-degraded region, along the deteriorated cable insulation extension;

- $\mathrm{R}_{\mathrm{nd}}^{\prime}$ - Equivalent resistance to the non-degraded region, along the deteriorated cable insulation extension.

\section{Performance Indexes at Estimating Degradation State of Insulated Cables}

Cables that exhibit varied degrees of degradation have, as a particular characteristic, the leakage current waveform with a third harmonic dominant effect as well as a small level of direct current [5]. Based on these assumptions, the work carried out under this research included the use of traditional degradation indexes [14] and new performance parameters, based on the nonlinear behavior of insulator degraded, as previously mentioned. The analysis procedures used are summarized in the sequence.

\section{A. Conventional Indicators}

- $\quad$ Dielectric power losses [1];

- Dielectric loss fator [1];

\section{B. Non-conventional Indicators}

- Total Harmonic Distortion (THD) of leakage current [1]

- Third harmonic amplitude (I3) of leakage current 
- Third harmonic phase angle ( $\theta 3)$ of leakage current [1].

- Equivalent parameters;

\section{New Indicators}

- Linearity indicator of VxI relationship - It is an indicator that relates the instantaneous values of applied voltage to the cable and their leakage currents, obtaining, consequently, correlations that express a larger or minor linearity relation. In the context of this paper, this strategy shows promise for the purposes outlined here. In light these facts, to characterize the level of non-linearity existent in the measurements, the Pearson Coefficient is used, as detailed in [15]. This factor comprises a range of variation from -1 to 1 and, the higher linearity of $\mathrm{VxI}$ relationship, nearest to 1 will be the value of such variable. For clarity of numerical indicator, this degradation index will use a greatness that expresses the percentual difference between the measured value and the unitary reference $(\Delta \rho \%)$.

$$
r=\frac{\sum(x i-\bar{X})(y i-\bar{Y})}{\sqrt{\sum(x i-\bar{X})^{2} \sum(y i-\bar{Y})^{2}}}
$$

\section{Case Studies and Validation of Diagnosis System}

The studies conducted and here reported comprise a synthesis of a large number of measurements and analysis carried out in the field and in a laboratory environment. From the different situations contemplated in the experimental tests, it was chosen to presentation the results of measurements concerning three insulated cables which compose an operational power supply system.

- Cable 1: XLPE insulation cable, cross section of $400 \mathrm{~mm}^{2}$, an approximated lenght of $3 \mathrm{~km}$ and voltage class of $8,7 / 15 \mathrm{KV}$. Although the installation of this cable ocurred 12 years ago, according to CEMIG maintenance people, this cable was not widely used till the experimental tests presented in this work;

- Cable 2: XLPE insulation, cross section of 400 $\mathrm{mm} 2$, an approximate length of $60 \mathrm{~m}$ and voltage class of 8,7/15 KV. It is operating more than 25 years;

- Cable 3: XLPE insulation, cross section of 400 $\mathrm{mm} 2$, an approximate length of $60 \mathrm{~m}$ and voltage class of $8,7 / 15 \mathrm{KV}$. It started operation only 6 months ago.

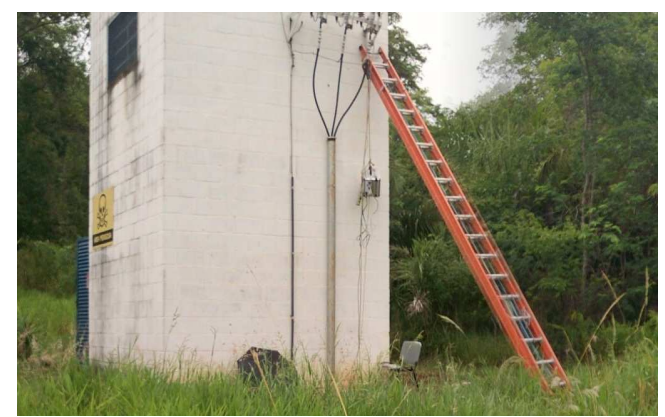

Fig. 7 - Sample 1

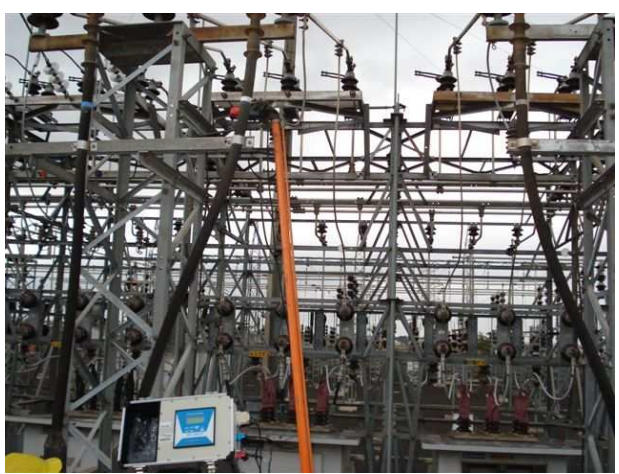

Fig. 8 - Sample 2

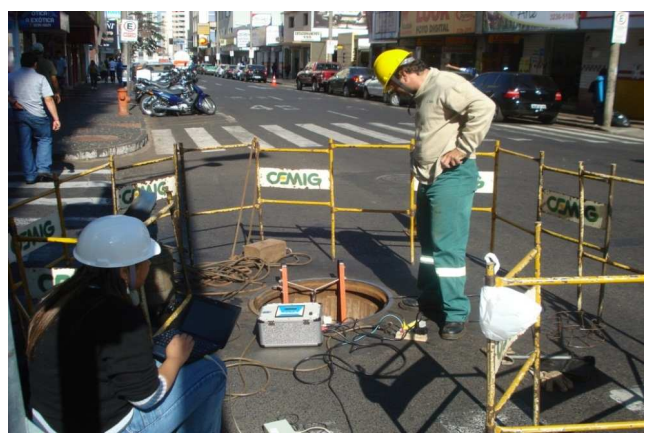

Fig. 9 - Sample 3

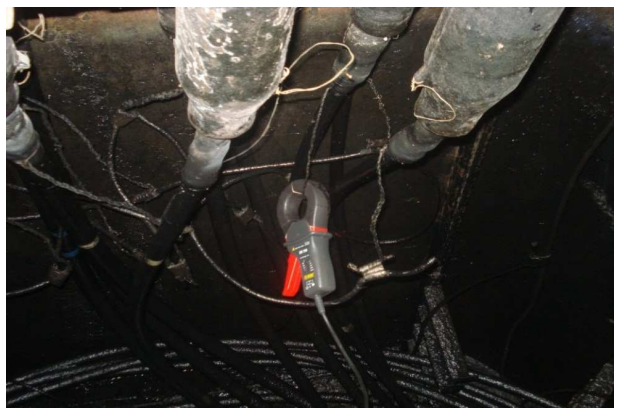

Fig. 10- Sample 3

Using an appropriate equipment to record voltage and current, with an analysis software based in the theory previously described and in accordance with [15], Fig 11, 12 and Fig. 13 show the waveforms extracted from the field tests concerning the leakage current and the applied voltage on the samples.

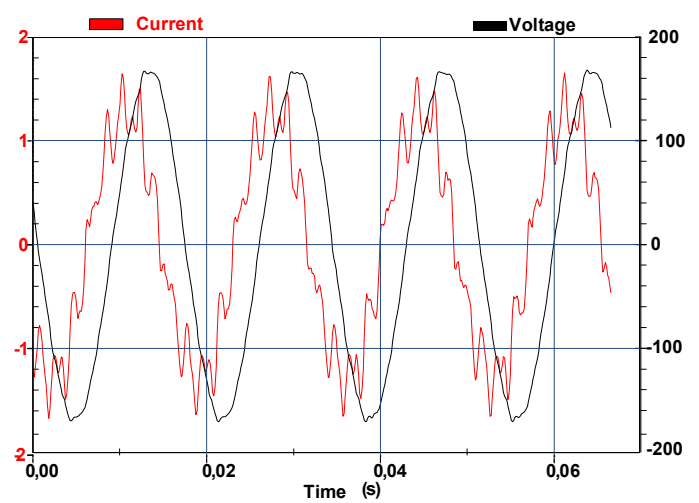

Fig. 10. - Sample 1: Applied voltage and leakage currents waveforms 


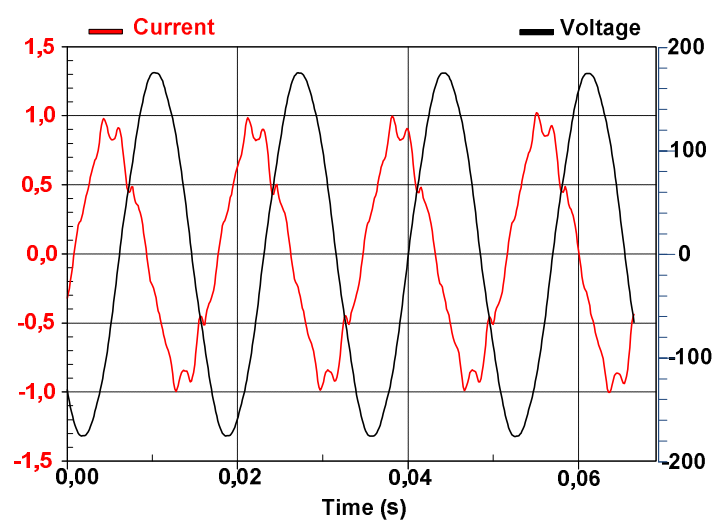

Fig. 11 - Sample 2: Applied voltage and leakage currents

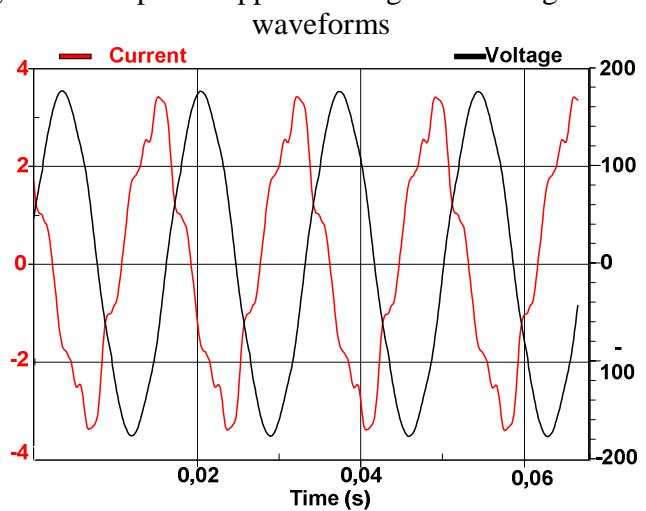

Fig. 12 - Sample 3: Applied voltage and leakage currents waveforms

From the recorded quantities and in consonance with the methodologies presented to obtain the performance indexes about the degradation state of insulated cables, it proceeds, in sequence, to the calculations that are intended to the knowledge of representative quantities about the operational conditions of cables employed in the diagnosis process here presented. As mentioned in the previously section, it will use the conventional and non-conventional procedures.

Figure 13 and Figure 14 show, respectively for Sample 1, 2 and Sample 3, the relationship between the applied voltage on the cable and the leakage current, arising of field measurements.

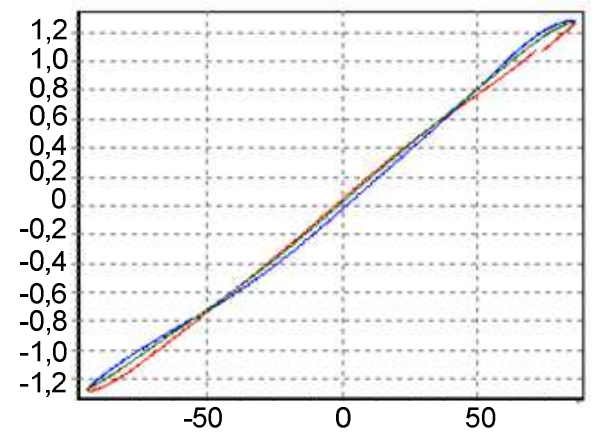

Fig. 13 - Sample 1: VxI relationship.

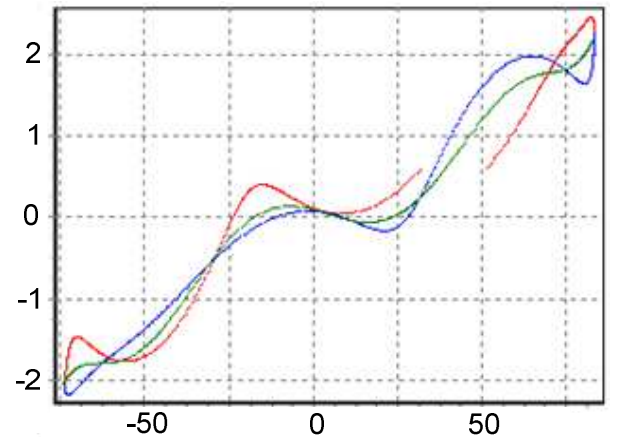

Fig. 14 - Sample 2: VxI relationship.

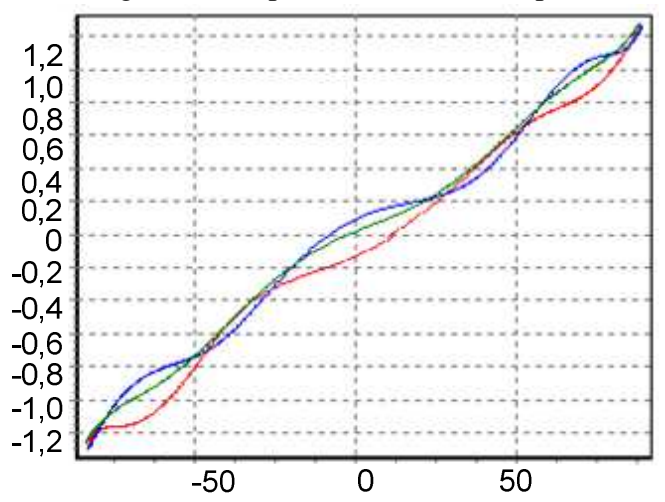

Fig. 15 - Sample 3: VxI relationship.

The measured data lead to results for the performance indexes, as previously established. Table 1 summarizes the main values found.

Table I - Synthesis of the obtained results

\begin{tabular}{|c|c|c|c|}
\hline $\begin{array}{c}\text { Performance } \\
\text { indexes }\end{array}$ & Sample 1 & Sample 2 & Sample 3 \\
\hline $\mathrm{P}(\mathrm{W} / \mathrm{m})$ & 4,56 & 25,52 & 6,97 \\
\hline $\mathrm{Tan} \delta$ & 0.54 & 0.574 & 0,966 \\
\hline THDI $(\%)$ & 3.189 & 3.3602666 & 1.8652502 \\
\hline $\mathrm{I} 3(\%)$ & 2.31 & 1.8098538 & 0.5370724 \\
\hline$\theta 3($ degrees) & 262.18 & 193.11035 & 160.14879 \\
\hline $\mathrm{R}(\mathrm{k} \Omega)$ & 0.141 & 0.3057524 & 0.0725478 \\
\hline $\mathrm{C}(\mathrm{nF})$ & 34.20 & 15079.106 & 37826.459 \\
\hline$\Delta \rho(\%)$ & 0,13 & 3,18 & 0,45 \\
\hline
\end{tabular}

Notwithstanding the fact that the values in Table 1 express the results obtained for the different quantities used for the diagnostic studies of operational conditions of the cable samples under tests, it appears that all indicators concerning the Sample 2 present values indicating a superior degradation state, when compared to Sample 1 and 3.

The indicator presented as Person Coefficient $(\Delta \mathrm{CP} \%)$ relatively to Sample 2 shows $3 \%$ of variation compared to the Sample 1, implying the non-linearity indexes is in accordance with the theory. However, it must be recognized that, for the present moment, the lack of a database that can be used as a comparative reference, allowing a critical and conclusive assessment about the subject. 


\section{Conclusions}

This paper was dedicated to the performance assessment of procedures currently established for the diagnosis of the operational conditions of insulated cables, as well as, to contribute to the diagnosis process by investigating an alternative procedure based on the relationship between the applied voltage on the power cable and their respective leakage current. Using appropriated measurement equipment which has been developed by the authors to perform field measurements, several tests were carried out on different samples of commercial cables. The results selected to presentation and discussions in this paper were related to three simples of cables chosen from a large number of cables forming the electrical grid of the local distribution company. The indicatives obtained have shown to be consistence with the established purposes here defined and the found figures have demonstrated that they apparently are reflecting their physical conditions, as relatively new and old components have been focused. Both traditional procedures and a new way to estimate the cable degradation have shown to be in agreement and this has pointed out that the proposal methodology based on the named Non-linearity Indicator seems to be promising. Finally, it is noteworthy that, although the results obtained are quite encouraging, the authors recognize that additional works should be conducted up to consolidate the methodology intended to estimation of the degradation state of the power cable insulation.

\section{Acknowledgment}

The authors express their gratitude to $\mathrm{CNPq}$, for the doctoral scholarship, and to CEMIG for the financial support through its $R \& D$ program (research project D368).

\section{References}

[1] A. T .Bulinski, E. So, S. S.Bamji, "Measurement of the Harmonic Distortion of the Insulation Loss Current as a Diagnostic Tool for High Voltage Cable Insulation," 07803-5935-6/00/\$10.00 @ 2000 IEEE, pp 1615-1620, 2000.

[2] T. Furuhashi, K. Tohyama, T. Imai, Y. Murata, "Dissipation Current Waveform of Water Tree Deteriorated Low Density Polyethylene Sheet”. Electrical Insulation and Dielectric Phenomena, 2006 IEEE Conference on, Oct. 1518 , pp 529-532, 2006.

[3] A. Nakajima, N. Kashiwagi, T. Murata, S. Takashi, O. Fukuda, S. Kital, K. Tokumaru, and K. Hirotau "Development of a hot-line diagnostic method for XLPE cables and the measurement results," IEEE Transactions on Power Delivery, vol.. 4, No. 2, April, pp. 857-862, 1989.

[4] S. Yamaguchi, S. Soda, N. Takada, "Development of a New Type Insulation Diagnostic Method for Hot-Line XLPE Cables", IEEE Transactions on Power Delivery, July, vol. 4 no. 3, pp. 1513-1520, 1989.

[5] T. Tsujimoto, M. Nakade, Y. Yagi, K. Adachi, H. Tanaka, Egasaki-cho, Tsurumi-ku, Yokohama, Kanagawa, Yawatakaigandori, Ichihara, Chiba, Higashi-shinagawa, Shinagawa-ku, "Development of ON-SITE Diagnostic for XLPE Cable by Harmonics in AC Loss Current," Proceedings of the 7th International Conference on Properties and Applications of Dielectric Materials, June 15, Nagoya, pp 73-76, 2003.
[6] T. Hashizume, C. Shinoda, T. Tani, and T. Taniguti, “A consideration on Life of XLPE cable by dry-curing process", 6th International Symposium on High Voltage Engineering, New Orleans, pp. 27-34, 1989.

[7] Wei. Zhang, Yutao Zhau, Baitun Yang, Yaonan Liu, "A Study on DC Component Method for Hot-Line XLPE Cable Diagnosis," IEEE International Symposium on Electrical Insulation, Pittsburgh - PA USA, June 5-8, pp 95-98, 1994.

[8] T. Ozaki, N. Ito, I. Sengoku, J. Kawai, and S. Nakamura, "Changes of capacitance and dielectric dissipation factor of water-treed XLPE with voltage,", Electrical Insulating Material, 2001. (ISEIM 2001). Proceedings of 2001 International Symposium ,Himeje, Japan, pp. 459-462, 2001.

[9] Wei. Zhang, Yutao Zhau, Baitun Yang, Yaonan Liu, “A Study on DC Component Method of On-Line Diagnosis for XLPE Cables," Proceedings of the 4th International Conference on Properties and Applications Dielectrics Materials, July 3-8, Brisbane Australia,vol.1 pp 375-378, 1994.

[10] F. N. Lima, "A contribution to the insulated cable operational performance estimation due to water tree phenomenon", $\mathrm{PhD}$. Thesis - Federal University of Uberlandia - Brazil, september 2008 - in portuguese.

[11] F. N. Lima, J. C. Oliveira, D. A. Andrade, et. all, "Modeling Water Tree Phenomenon for Insulated Cable Loss Current Estimation", In: IEEE PES Transmission and Distribution Conference and Exposition: Latin America, pp. $1-6,2008$.

[12] L. N. Velasco, J. C. Oliveira, L. C. G. Freitas, A. Andrade, F.N. Lima, A.P. Finazzi "A strategy towards the degradation estimation of insulated cables throught performance indicator measurements" in Proc. of IX Induscon - 9th IEEE/IAS International Conference on Industry, November 2010

[13] L. N. Velasco, T.V. Silva, J. C. Oliveira, L. C. G. Freitas, F. P. Santilio, F.N. Lima, A.P. Finazzi, H. C. Martins, W. J. Araujo, J. M. Borges, "An Approach to Improve Power Supply Continuity throughout the Estimation of Insulated Power Cable Life Expectance Indexes" in Proc. of XI COBEP- Brazilian Conference on Power Electronics, September 2011

[14] Y. Yukihiro., T. Hideo and K. Hitoshi. "Study on Diagnostic Method for Water Treed XLPE Cable by Loss Current Measurement," 0-7803-53035-9/98/\$10.00@ 1998 IEEE, pp 653-656, 1998.

[15] S. A. Lira, "Correlation Analysis: Theoretical Approach and Construction of Coefficients with Applications", Ms.C. Dissertation, Federal University of Parana, Curitiba, 2004. 